\title{
Clichés Lingüisticos y Ambigüedad en Pedro Páramo
}

\author{
In language and in the use of language, duplicity plays a \\ cardinal role. \\ Roman Jakobson
}

Rulfo ha declarado que al escribir Pedro Páramo resolvió el problema de la "búsqueda de estilo" utilizando "el lenguaje del pueblo, el lenguaje hablado que había oỉdo de mis mayores". 1 Para que esa declaración no llame a engaño conviene trasladarla a una ecuación más especifica: Rulfo se ha valido de la lengua del pueblo, asediándola, para descubrir toda su ambigüedad y por medio de ella reflejar duplicidades que sustentan el texto en todos sus niveles. Los personajes se relevan, sus atributos y funciones se superponen; las situaciones se reproducen con ligeras variantes en momentos cruciales; los destinos de unos personajes condicionan, preparan o reiteran los de otros. También, ciertos tópicos universales, desmembrados, se literalizan y son incluidos como elementos anecdóticos nunca independientes del contex to. ${ }^{2}$

En el nivel más estrictamente léxico, se destaca el especial uso polisémico que se hace en Pedro Páramo no sólo del discurso mimético -del "lenguaje del pueblo"- - sino, dentro de él, de ciertas estructuras organizadas como sintagmas fijos dentro de la lengua, especialmente dentro de la dicción oral: coloquial y popular. Según su grado de consolidación, esas estructuras son gramatical y sintácticamente clichés - frases hechas-o giros idiomáticos; ${ }^{3}$ en todo caso, se trata de formas más o menos fijas que parecerïan haber solidificado los signos que las integran en un solo significante con un significado único. Los clichés o frases hechas tienen en común con los refranes 
cierto tono sentencioso, además de la organización fija. Pero difieren de ellos por la relativa contingencia del enunciado: aunque estable, su significado es -por lo menos en el habla habitual- puramente connotativo, lo cual inhabilita a los clichés o frases hechas para aserciones generalizadoras. Porque siempre requieren un referente, no pueden apuntar, como lo hacen máximas y refranes, a una pretendidamente taxativa enunciación de verdades universales. 4

El empleo de esos sintagmas en Pedro Páramo hace cuestionables las afirmaciones precedentes: sistemáticamente, cuando se usan en la novela sintagmas consolidados en la lengua como clichés es para socavarlos hasta el punto de conferirles una suerte de flexibilidad que equivale a la arbitrariedad y a la capacidad polisémica de los signos independientes. Pero como a la vez pareciera imposible despojarlos de la carga propia - aparentemente indestructible-debida a su calidad de fórmulas fijas, su uso refuerza la ambigüedad del tex to de una manera en que no podrían hacerlo signos independientes. Por lo demás - varios críticos lo han consignado- los signos independientes a menudo se reiteran en Pedro Páramo con múltiples connotaciones. En estas páginas me limitaré a dar algunos ejemplos de la versatilidad que Rulfo descubre -que revela - en una gama de sintagmas que recorre todos los grados de la consolidación.

"Al comienzo de la novela, los enunciados de Juan Preciado instauran el equîvoco en el nivel temático. El hijo, determinado a no cumplir la promesa hecha a su madre, se ha llenado de la ilusión de encontrar a su padre. Esa ilusión motiva el viaje a Comala, pedido por la madre. Yuxtapuesto a esos enunciados iniciales, el diálogo entablado con Abundio reitera, en otro registro, que la inteligibilidad del texto requiere su lectura total. El intercambio, en el que aparecen por primera vez en la novela clichés del discurso oral, es acaso -irónicamente- una de las cifras más significativas entre la multitud de equǐvocos de Pedro Páramo. " ¿ ¿Y a qué va usted a Comala, si se puede saber?" (p. 8), ${ }^{5}$ pregunta Abundio a Juan Preciado inmediatamente de iniciado el diálogo. Esa fórmula casi neutra de cortesía precede a un significativo núcleo de ambigüedades:

-Voy a ver a mi padre -contesté.

- ¡Ah! -dijo él.

$\mathrm{Y}$ volvimos al silencio.

$[\ldots]$

-Bonita fiesta le va a armar-volvǐ a oir la voz del que iba allí a mi lado-. Se pondrá contento de ver a alguien 
después de tantos años que nadie viene por aquï.

Luego añadió:

-Sea usted quien sea, se alegrará de verlo. (p. 9)

La aseveración de Abundio - "bonita fiesta le va a armar"- es una anticipación ominosa en su socarronería. Como es sabido, el cliché significa, por antífrasis, 'usted lo va a pasar mal'. 6 Sin embargo, el sintagma siguiente - "se pondrá contento"- , simple giro idiomático y por lo tanto más ambivalente que "bonita fiesta...", podría admitir un sentido literal. ${ }^{7} \mathrm{Y}$ aunque el contexto descarte la literali$\mathrm{dad}$, se produce un temporario efecto engañoso, que aparenta anular la antífrasis. Como resultado, toda la enunciación de Abundio permanece suspendida entre dos significados. Pero el equivoco vuelve a acentuarse: el signo fiesta, independizado del sintagma, remite a uno de los núcleos temáticos de la novela: la ruina de Comala por venganza de Pedro Páramo:

-Se ha muerto doña Susana.

$[\ldots]$

Comenzó a llegar gente de otros rumbos, atraída por el constante repique. De Contla venïan como en peregrinación. Y aun de más lejos. [...] Y así poco a poco la cosa se convirtió en fiesta. [...]

Don Pedro no hablaba. No salía de su cuarto. Juró vengarse de Comala. (p. 121)

No parece exagerado apuntar que la fiesta literal que el pueblo de Comala organizó en medio del duelo de Pedro Páramo es una explicitación del sentido irónico de la antífrasis (bonita fiesta le armó el pueblo a Pedro Páramo). Además, son sin duda los ecos de esa fiesta remota, petrificada en la Comala fantasmal, los que percibía Damiana Cisneros, que después de la muerte de Susana permaneció parapetada en la Media Luna junto a Pedro Páramo ("Hasta acá llegaba la luz del pueblo, que parecǐa una aureola sobre el cielo gris. Porque fueron días grises, tristes para la Media Luna".) (p. 121):

-Hubo un tiempo que estuve oyendo durante muchas noches el rumor de una fiesta. Me llegaban los ruidos hasta la Media Luna. Me acerqué para ver el mitote aquel y vi esto: lo que estamos viendo ahora. Nada. Nadie. Las calles tan solas como ahora.

Luego dejé de oîrla. (p. 45) 
Volvamos al diálogo entre Abundio y Juan Preciado: la declaración "Sea usted quien sea, se alegrará de verlo" marca un hiato antes de que se revele el parentesco de los dos hijos de Pedro Páramo. Con ese sintagma -por su significado muy codificado como convención social - otra vez se aparenta atenuar el equívoco. Con todo, el sintagma es también dúplice. El primer miembro -sea usted quien seatrasluce la curiosidad de Abundio a la vez que alude cripticamente al motivo del viaje de Juan Preciado (buscar al padre es buscar quién se es). El texto retoma disimuladamente el presagio, bajo la especie de otro registro: en la descripción de un paisaje evanescente -cuyas linneas y formas se esfuman unas en otras- que ofrece acaso menos punto de apoyo que el diálogo ambiguo. 8

Después de enterarse del motivo genérico del viaje de Juan Preciado a Comala, repite Abundio la fórmula de cortesía para averiguar quién es el padre objeto de la busca:

- ¿Y qué trazas tiene su padre, si se puede saber?

-No lo conozco -le dije-. Sólo sé que se llama Pedro Páramo.

$$
\text { -Y..] también soy hijo de Pedro Páramo -me dijo. (p. 9) }
$$

La aventura de Comala revelará -implacable, aunque fragmentaria, oscuramente - a Juan Preciado que el motivo de su viaje no se podía saber. Capta la imposibilidad cuando es demasiado tarde y sólo le queda no proporcionar a Donis, el incestuoso, la información completa que había dado a Abundio. 9

El diálogo siguiente comienza encubriendo sardónicamente la terrible semejanza entre Comala y el infierno y culmina con un malentendido:

-Hace calor aquí-dije.

-Sí, y esto no es nada -me contestó el otro-. Cálmese. Ya lo sentirá más fuerte cuando lleguemos a Comala. Aquello está $[\ldots]$ en la mera boca del infierno. Con decirle que muchos de los que allí se mueren, al llegar al infierno regresan por su cobija.

- ¿Conoce usted a Pedro Páramo? -le pregunté. Me atreví a hacerlo porque vi en sus ojos una gota de confianza.

-¿Quién es? -volvĭ a preguntar.

-Un rencor vivo -me contestó él (pp. 9-10) 
La designación de Pedro Páramo como "un rencor vivo" apoya su equívoco sobre todo en el verbo en presente de la pregunta de Juan Preciado ("¿quién es?"), de alcance distinto para él y para el fantasma de Abundio. Dentro del sintagma, vivo connota 'personificado' -significante apto también para las cualidades de un muerto: Pedro Páramo era -o fue- un rencor vivo; pero el verbo en presente destaca el significado de 'viviente'.10 Además, otra vez -como en el caso de bonita fiesta - uno de los componentes del sintagma remite, en cuanto significante independiente, a un doble núcleo temático: el rencor que determinó la mortandad causada por Pedro Páramo después de la muerte accidental de su padre; el rencor que determinó la ruina de Comala después de la fiesta en que el pueblo transformó el duelo por Susana San Juan 11

El final del diálogo - serie de malentendidos con que culmina la secuencia- entreteje juegos de palabras y clichés del discurso oral:

El caso es que nuestras madres nos malparieron en un petate aunque éramos hijos de Pedro Páramo. Y lo más chistoso es que él nos llevó a bautizar. Con usted debe haber pasadolo mismo, ¿no?

-No me acuerdo.

- ¡Váyase mucho al carajo!

- ¿Qué dice usted?

-Que ya estamos llegando, señor.

-Sĭ, ya lo veo. ¿Qué pasó por aquî?

-Un correcaminos, señor. Asï les nombran a estos pájaros.

-No, yo preguntaba por el pueblo, que se ve tan solo, como si estuviera abandonado. Parece que no lo habitara nadie.

-No es que lo parezca. Asī es. Aquí no vive nadie.

- ¿Y Pedro Páramo?

-Pedro Páramo murió hace muchos años. (p. 11)

La gradación de escamoteos - Juan Preciado, para no reconocerse su hermano, replica "No me acuerdo" al comentario de Abundio con respecto a su posible origen bastardo ("nuestras madres nos malparieron en un petate"12), y la ironía elude una posible aclaración: pese a llevar, como bastardo, el apellido materno, Juan Preciado era hijo legítimo de Pedro Páramo; Abundio no se atreve a mantener el insulto cuando Juan Preciado lo encara; el fácil recurso a la polisemia 
("¿qué pasó por aquí?" ") - acusa lo sorprendente de la segunda revelación. Además de haber sido también padre de Abundio, "Pedro Páramo murió hace muchos años". Más allá de su mero carácter de discurso mimético -inocuo sólo en un nivel superficial- la serie de evasivas es parte de un continuum sostenidamente especioso, al que integra y refleja.

La cohesión final del texto de Pedro Páramo se debe a que no hay duplicaciones simétricas de situaciones o atributos de los personajes, como tampoco se manipulan las fórmulas fijas de manera mecánica. La fiesta macabra que siguió a la muerte de Susana se anticipa otra vez subrepticiamente, en la polisemia cazurra de los peones que acarrearon el féretro de Miguel Páramo:

-A mi me dolió mucho ese muerto -dijo Terencio Lubianes. Todavia traigo adoloridos los hombros.

-Y a mí -dijo su hermano Ubillado-. Hasta se me agrandaron los juanetes. Con eso de que el patrón quiso que todos fuésemos de zapatos. Ni que hubiera sido dỉa de fiesta, ¿verdad Toribio? (pp. 32-33)

Otra vez, el signo fiesta está integrado en un contexto que remite a otro; en este aspecto, esta secuencia es comparable a las que remiten a la involuntaria celebración de la muerte de Susana: especialmente a la declaración de Abundio en su diálogo con Juan Preciado comentada al principio de estas páginas. Pero tanto el tratamiento de la frase hecha -que aquí es claramente irónico- como la situación del signo fiesta dentro de la secuencia difieren. También difieren las reacciones ante la muerte de Miguel y la de Susana. Salvo Pedro Páramo, Eduviges y Damiana nadie quería a Miguel; Susana más bien inspiraba piedad. Adviértase que el dolor físico que la muerte de Miguel causó a algunos habitantes de Comala está anticipado con un tono grave, hasta ceremonioso, que no harĭa prever la mordacidad de los peones:

Aquel cadáver pesaba mucho en el ánimo de todos.

Estaba sobre una tarima, en medio de la iglesia, rodeado de cirios nuevos, de flores, de un padre que estaba detrás de él, solo, esperando que terminara la velación. (p. 29)

Estas repeticiones en lo diverso dan su carácter paradigmático a la escritura de Pedro Páramo. 13

No sólo las repeticiones se ensamblan en lo diverso: también varìa la manera en que las organizaciones paradigmáticas se combinan 
alrededor de un núcleo. Véanse por ejemplo algunos desarrollos centrados en el asesinato de Toribio Aldrete, que interesan aquí por la inserción y el tratamiento de los clichés.

Damiana Cisneros denota lacónicamente el origen del grito que aterrorizó a Juan Preciado en la casa de Eduviges: "-Tal vez sea algún eco que está aquí encerrado. En este cuarto ahorcaron a Toribio Aldrete hace mucho tiempo" (p. 37). ${ }^{14}$ En las secuencias siguientes, el narrador omnisciente se explaya en detalles de los atropellos concebidos por Pedro Páramo y ejecutados por Fulgor Sedano. En esas secuencias, el punto de vista de la tercera persona-que alterna entre el narrador y los personajes - alternadamente aproxima y aleja el discurso referido. Debido a la perspectiva múltiple que se establece, el discurso de Toribio Aldrete - textura de frases hechas que roza el patetismo- aparenta, curiosamente, cierto desapego que hasta parece quitar relieve a los insultos:

-A usted ni quien le quite lo hombre, don Fulgor. Sé que usted las puede. Y no por el poder que tiene atrás, sino por usted mismo.

Se acordaba. Fue lo primero que le dijo el Aldrete, después que se habian estado emborrachando juntos, dizque para celebrar el acta: -Con ese papel nos vamos a limpiar usted y yo, don Fulgor, porque no va a servir para otra cosa. [...] En fin, por lo que a usted respecta, [...] me quitó de apuraciones; porque me tenía usted preocupado, lo que sea de cada quien. [...]

Se acordaba. Estaban en la fonda de Eduviges. [...]

-Pues ya le digo, don Fulgor -le dijo Toribio Aldrete-. A usted ni quien le menoscabe lo hombre que es; pero me lleva la rejodida con ese hijo de la rechintola de su patrón. (pp. 37-38)

Dos de los clichés del ahorcado son trasladados sarcásticamente del código de Toribio Aldrete al de Fulgor Sedano; uno, sigue y concluye la secuencia reproducida en parte más arriba:

Se acordaba. Fue lo último que le oyó decir en sus cinco sentidos. Después se había comportado como un collón, dando de gritos. "Dizque la fuerza que yo tenia atrás. ¡Vaya!" (p. 38)

Páginas más adelante, se retoma la secuencia: Fulgor Sedano va a informar a Pedro Páramo que el asunto de Toribio Aldrete "está 
liquidado"; mientras espera que le abran la puerta, se fija en los dos moños de luto - por el abuelo de Pedro Páramo (p. 18) y por el padre-superpuestos con años de diferencia:

Tocó nuevamente con el mango del chicote, nada más por insistir [...] Dijo mirando el dintel de la puerta: "Se ven bonitos esos moños negros, lo que sea de cada quien". (pp. 44-45)

La ironǐa macabra de las duplicaciones muestra ejemplarmente la tenuidad del sentido de estos clichés. ${ }^{15} \mathrm{Su}$ vacuidad misma les permite cumplir, en el contexto, una función neutralizadora: el sarcasmo descarta matices, no caben la compasión ni la piedad; el horror queda expuesto en estado puro.

Una analogía arcana aproxima a Juan Preciado y Pedro Páramo. Para mostrar cómo los dos van "demasiado lejos", se desarrolla el motivo de la ilusión -de conseguir al padre; de lograr el amor de Susana. La analogía entre padre e hijo está concertada en secuencias que funcionan como metonimias del tópico "traspasar los límites". 16 Léxicamente, el cliché pagar caro recalca la analogǐa. Fulgor Sedano advierte a Pedro Páramo: "-Porque la familia de usted lo absorbió todo. Pedīan y pedǐan, sin devolver nada. Eso se paga caro" (p. 40). Dorotea replica a Juan Preciado, que reconoce haber viajado a Comala impulsado por la ilusión: "- ¿La ilusión? Eso cuesta caro" (p. 64). Por fin, al enterarse de la muerte de Miguel, Pedro Páramo reconoce: "-Estoy empezando a pagar. Más vale empezar temprano, para terminar pronto" (p. 72).

Caba agregar aquí que aunque no faltan sintagmas de tono sentencioso -como los clichés citados en el párrafo anterior y numerosas expresiones no totalmente codificadas-17 hay en la novela un único refrán. "Usted ha de venir cansado y el sueño es muy buen colchón para el cansancio" (p. 14)-con que Eduviges replica a la observación de Juan Preciado de que no hay cama en el cuarto que le ha destinado - trasciende la que podría ser su obvia función inmediata: subrayar la inconsistencia de esta clase de sintagmas. Ya la aplicación de una trivialidad extrema a una experiencia limite -como la que está viviendo Juan Preciado- implica que el acoplamiento no debe leerse como pura ironía ni como mera paradoja. Por lo demás, al remitir -como lo hace - a una de las secuencias culminantes del texto (Juan Preciado llega extenuado de pavor a la casa de los incestuosos $\mathrm{y}$, literalmente, usa el sueño como colchón para su can- 
sancio (pp. 51-54), lo que no pudo lograr en la cámara fúnebre donde lo instaló Eduviges), el sintagma prima facie fútil se reivindica como unidad potencialmente expresiva.

Los ejemplos analizados manifiestan una obvia $-\mathrm{y}$ fecundaactitud crítica ante las fórmulas fijas del discurso oral. Al socavarlas, se logran dos efectos. El primero - sin duda el más importante en lo que al tex to de la novela respecta - es el de sacar a la luz polisemias inesperadas, cuya verosimilitud contextual es también referencial: imposible dudar la afirmación de Rulfo en cuanto al habla del pueblo mexicano. Los empleos de las fórmulas son, como se ha visto, variados: la frase hecha se usa como indicio temático (bonita fiesta); una sinécdoque corriente y estereotipada (rencor vivo) sufre un aparente proceso de literalización; los juegos fáciles de palabras sirven, metafóricamente, para reflejar otros malentendidos, en que el texto abunda; los clichés neutralizados y desgastados por el uso se reactivan, como si se tratara de signos individuales, más hábiles que los sintagmas (el poder que tiene atrás; lo que sea de cada quien). Por fin, una fórmula ("pagar caro" o "costar caro") se usa estrictamente en su sentido metafórico codificado. 18

El segundo efecto es el de mostrar, por el contraste flagrante entre la letra de las fórmulas usadas y sus connotaciones textuales, que el discurso literario de Rulfo se libera de toda parálisis inexpresiva tanto porque los recursos no se repiten mecánicamente como porque trascienden la reproducción puramente mimética del habla. También es interesante advertir que el texto mismo parece insinuar lateralmente, en dos pasajes, el peligro latente -la potencial carencia dé sentido- en el apego fetichista a las fórmulas rígidas:

Ya lo decía yo: "A la larga acabarán con todo. Bueno, pues acabaron. Aunque hay por aquil quien se interese en comprar los terrenos. [...] Se podrían cubrir las libranzas pendientes y todavía quedaría algo; aunque, eso sí, algo mermado.

- ¿No serás tú?

- ¡Cómo se pone a creer que yo!

-Yo creo hasta el bendito [....]. (p. 40)

-Anoche vino y la confesó. Hoy debía de haber comulgado, pero no debe estar en gracia porque el padre Rentería no le ha traỉdo la comunión. Dijo que lo haria a hora temprana, y ya ve usted, el sol ya está aquí y no ha venido. No debe estar en gracia. 
- ¿En gracia de quién?

-De Dios, señor.

-No seas tonta, Justina. (p. 114)

El trastrueque del sentido popular de el bendito - pauta suprema de veracidad- en su opuesto, asi como la ignorancia del referente de Dios -implícito en el mundo católico en la fórmula en gracia-son claras marcas de la irreverencia de Pedro Páramo, manifestaciones de su idiosincracia autárquica, que el texto explicita con insistencia. Ya muy pronto Pedro Páramo anunció a Fulgor Sedano: "La ley de ahora en adelante la vamos a hacer nosotros" (p. 44). "Hacer la ley" quiere decir -entre otras cosas- romper, ignorar y también acep$\operatorname{tar}^{19}$ clichés si es conveniente: la imprevisibilidad es una de las fuerzas del cacique.

Pero esas no son las únicas lecturas de los clichés. La adulteración del significado fuertemente socializado de "no creer $n i$ el bendito" y la exclusión del determinante de Dios -único que el sintagma en gracia sobreentiende en el ámbito del español- implican una reducción al absurdo de esos sentidos socializados. Como si el discurso de Pedro Páramo propusiera, mientras despliega la productividad subyacente aun en las organizaciones sintácticas más fijas de la lengua, una denuncia; como si mostrara, por añadidura y por contraste implñicito, la estolidez de una escritura ceñida a la reproducción mecánica -sin distancia- de cualquier dicción fuertemente codificada.

Parece redundante $-\mathrm{y}$ hasta escolar - insistir en que la novela de Rulfo posee una combinación de logros sobresalientes. Pero acaso, a veintidós años de su publicación valga la pena resumir la calidad de esos logros: reactivación y reducción de mitos universales, no por simple adaptación, sino por sinntesis y superposición de funciones arquetípicas; tratamiento lírico de la materia narrativa; huecos narrativos que son funcionales, pues remiten a transformaciones o analogías del contexto; 20 lúcido e implacable control, que somete los referentes extratextuales 21 a las necesidades anecdóticas. Resulta pertinente subrayar como uno de los sustentos principales de esos valores la utilización no paródica, no documental sino marcadamente irónica, dúplice, de los aspectos más imitables y más tipificadores del habla popular. Esa utilización ha dado como resultado una de las obras más anticonvencionales de una literatura -la de lengua espa- 
ñola- que viene luchando con despareja fortuna en los últimos cincuenta años por liberarse del mimetismo y del amaneramiento.

Herbert H. Lehman College, CUNY

MARIA LUISA BASTOS

\section{NOTAS}

1. Cf. Joseph Sommers, "Entrevista", Hispamérica, 4/5 (1973), 103-107. Recogida en La narrativa de Juan Rulfo. Interpretaciones críticas (México: Secretarìa de Educación Pública, 1974).

2. Cf. María Luisa Bastos y Sylvia Molloy, "La estrella junto a la luna: variantes de la figura materna en Pedro Páramo", $M L N, 92$ (1977). En otro trabajo trataré de mostrar cómo Rulfo utiliza tópicos universales como elementos literales del relato.

3. Cliché o clisé se han estado empleando en español con su connotación metafórica desde principios de siglo. Cf. Julio Casares, Crítica profana (Madrid: Imprenta Colonial, 1916), p. 297 y siguientes. El Diccionario de la Real Academia Española incluye, finalmente, los términos con esa connotación en el suplemento de la edición de 1970: 'lugar común, idea o expresión demasiado repetida o formularia'. En este trabajo empleo indistintamente cliché, fórmula fija, frase hecha para designar los sintagmas fuertemente consolidados, que el Diccionario de Autoridades define bajo frase hecha como 'Locución enérgica y por lo común metafórica, con la que se significa más de lo que se expresa u otra cosa de lo que indica la letra'.

Diccionarios y gramáticas del español usan anárquicamente -superponiendo y hasta contradiciendo las acepciones-locución, frase hecha, frase proverbial, giro idiomático, expresipon idiomática, idiotismo. La anarquia ya fue advertida por Julio Casares, quien intentó remediarla en Introducción a la lexicografía moderna (Madrid: Revista de Filologïa Española, Anejo LII, 1950): Empleo en este trabajo giros idiomáticos en el sentido de 'maneras peculiares de un idioma de construir determinadas expresiones. [...] no es una expresión invariable construida con elementos fijos, sino una manera de construir aplicable a múltiples casos' (María Moliner, subrayado mío). La manera de construir, el molde -fijo en cuanto esquema de sintagma-, establece una relación indudable entre esas determinadas expresiones y los clichés.

4. Julio Casares percibió la diferencia entre lo que él llama frase proverbial y el proverbio: "la frase proverbial tiene el carácter de un dicho que arranca de un caso único y concreto, real o fingido, y que se sitúa en el pasado. [...] El proceso lingüistico creador quedó cerrado una vez forjada la frase, y su aplicación tendrá siempre el valor de una cita. [...] El proverbio, en general, como fruto de experiencias acumuladas, tiene su fundamento en el pasado pero nace de cara al porvenir". Op. cit, p. 194. 
5. Juan Rulfo, Pedro Páramo (México: Fondo de Cultura Económica, 1966). Todas las citas corresponden a esta edición. Todos los subrayados son mios, salvo indicación contraria.

6. Cf. Werner Beinhauer, El español coloquial (Madrid: Gredos, 1968), p. 194, n. 39:, "Vicente Garcia de Diego, en Lingüística general y española, p. 353, define acertadamente la ironía como 'paradoja semántica humorǐstica [. . . , el sentido es una adivinación para el interlocutor' (por ej., ¡bonito negocio!)." Subrayado del autor.

7. El sintagma ponerse contento es un giro idiomático. Cf. supra, nota 3.

8. "En la reverberación del sol, la llanura parecía una laguna transparente, deshecha en vapores por donde se traslucía un horizonte gris. Y más allá, una lǐnea de montañas. Y todavía más allá, la más remota lejania" (p. 9).

9. Juan Preciado responde a Donis con deliberada reticencia: "Entonces alguien me tocó los hombros.

- ¿Qué hace usted por aquí?

-Vine a buscar. .. -y ya iba a decir a quién, cuando me detuve-: vine a buscar a mi padre"' (p. 50).

10. Es curiosa la organización de este tipo de giros idiomáticos, sintagmas cuyo núcleo es lo que Pierre Fontanier llama "synecdoque d'abstraction absolue" (cf. Pierre Fontanier, Les Figures du Discours, Paris: Flammarion, 1968 , p. 95). Rencor ha sido abstraído de hombre rencoroso; luego, un procedimiento metafórico -el adjetivo vivo-refuerza, como reintegrándola en el orden de lo concreto, la abstracción que originó la sinécdoque. Véase, en el cuento "Anacleto Morones", cómo se juega con el doble significado de diablo y cómo se establece una sinécdoque similar:

"Si no estuviera de por medio que eres el yerno del Santo Niño, no te vendrǐamos a buscar, contimás te pediríamos nada. Siempre has sido muy diablo, Lucas Lucatero.

-Por algo fui ayudante de Anacleto Morones. El sĩ que era el vivo demonio." El llano en llamas (México: Fondo de Cultura Económica, 1965), p. 135.

Marǐa Moliner da como modelos de estos giros ejemplo vivo, viva estampa.

11. "Pedro Páramo causó tal mortandad después que le mataron a su padre, que se dice casi acabó con los asistentes a la boda en la cual don Lucas Páramo iba a fungir de padrino" (p. 83). "Hasta acá llegaba la luz del pueblo, que parecía una aureola sobre el cielo gris. [...] Don Pedro no hablaba. No salǐa del cuarto. Juró vengarse de Comala" (p. 121).

12. En México, nacer en un petate -en una estera- significa ser bastardo. Cf. el refrán "El que ha nacido en un petate, siempre anda apestando a tule", citado por Francisco de Santamaría, Diccionario de Mejicanismos (México: Editorial Porrúa, S.A., 1974).

13. Cf. Roland Barthes, Le Degré Zéro de l'Ecriture (Utrecht: Editions Gonthier, 1965), p. 132: "Depuis Saussure, l'analyse du plan associatif a reçu un développement considérable; son nom même a changé; on parle aujourd'hui, non 
de plan associatif, mais de plan paradigmatique [...] le plan associatif est évidemment lié de très près a la 'langue' comme système alors que le syntagme est plus proche de la parole." Subrayado del autor.

Cf. también A.J. Greimas, Sémantique structurale (Paris: Flammarion, 1966), p. 40 '“ [...] les sèmes, les lexèmes et les énoncés qui s'y rencontrent peuvent entretenir entre eux des relations de conjonction ou de disjonction [...] Les premières manifesteront, à l'intérieur du discours, des unités situées sur la dimension paradigmatique, tandis que les secondes établiront, dans le même discours, la dimension syntagmatique." Subrayados mǐos.

14. El discurso de Damiana Cisneros la muestra como personaje adherido fielmente a las pautas establecidas por Pedro Páramo. Así lo manifiesta su desasimiento frente a la suerte terrenal de Toribio Aldrete y frente al destino de ultratumba de Eduviges, a quien el padre Renterǐa negó ostensiblemente la absolución por suicida. Cf. las súplicas inútiles de Maria Dyada (pp. 34-35) y la escueta declaración de Damiana Cisneros a Juan Preciado: "Pobre Eduviges. Debe de andar penando todavia" (p. 37). O la actitud de clara entrega de Damiana a la voluntad de Pedro Páramo: "[...] con habérmelo avisado, yo le hubiera dicho a la Margarita que el patrón la necesitaba para esta noche, y él no habría tenido ni la molestia de levantarse de su cama. [...]

Después volvió a oir otros golpes; pero contra la puerta grande, como si la estuvieran aporreando a culatazos. [...] Una lámpara regó su luz sobre la cara de algunos hombres. Después se apagó. 'Son cosas que a mí no me interesan', dijo Damiana Cisneros, y cerró la ventana" (pp. 110-111).

15. La intercambiabilidad de muchos clichés los emparienta con los shifters. Fulgor Sedano reacomoda las expresiones de Toribio Aldrete en un estilo peculiar: dificil de encasillar en las categorias tradicionales de directo o indirecto porque parecen participar a la vez de ambas. Por eso, aunque simulan ser reproducciones literales, también entran sin dificultad en la categoría $M / M$, de "reported speech" descripta por Roman Jakobson: "shifters are distinguished from all other constituents of the linguistic code solely by their compulsory reference to the given message." Roman Jakobson, Selected Writings (The Hague, Paris: Mouton, 1971), II, 131. También parecen aquil pertinentes las observaciones de Barthes con respecto al sintagma: "la 'proximité' structurale du syntagme et de la parole est un fait important [...] parce qu'elle permet d'expliquer structuralement certains phénomènes de 'naturalisation' des discours connotés." Roland Barthes, op. cit., p. 136.

16. Rulfo anecdotiza y transforma en actantes del relato elementos literales de tópicos universales. Cf., para el concepto y las "funciones" de los actantes, A.J. Greimas, op. cit., p. 122 y pp. 172-186. Se lleva a cabo, en Pedro Páramo, para esa concreción de las aristotélicas "líneas generales de argumentos", un proceso metonímico. Por ejemplo, muchas secuencias cuyas anécdotas constituyen "episodios" diferentes, muestran cómo Pedro Páramo "traspasó los límites" o "fue muy lejos": el casamiento con Dolores para no pagar lo que debía a las Preciado; el asesinato de Toribio Aldrete; la manipulación del padre 
Rentería para que diese la absolución post mortem a Miguel; la estratagema para que Bartolomé San Juan y Susana regresaran a Comala; su actitud con los cristeros. Las aventuras de Miguel son representaciones de cómo traspasó los límites, y el viaje mismo de Juan Preciado es una expansión metonímica de "ir más lejos".

17. Véanse unas pocas muestras: "Que se resignen otros, abuela, yo no estoy para resignaciones" (p. 24); "Y es que la alegrĭa cansa" (p. 45). "[...] Suspiraba mucho. -Eso es malo. Cada suspiro es como un sorbo de vida del que uno se deshace" (p. 46); "Y la vergüenza no cura" (p. 56).

18. En el cuento "El llano en llamas" se restituye a las frases hechas su sentido literal: "Y el que costó más trabajo fue aquel caporal flaco y largo como garrocha de otate, que escurría el bulto sólo con ladearse un poquito. En cambio el administrador se murió luego luego. Estaba chaparrito y ovachón y no usó ninguna maña para sacarle el cuerpo al verduguillo. Se murió muy callado, casi sin moverse y como si él mismo hubiera querido ensartarse. [...]

[...] Ibamos mero en medio de la noche, con los ojos aturdidos de sueño y con la idea ida; pero él, que nos conocía a todos, nos hablaba para que levantáramos cabeza. [...]

[...] Subimos a los montes más altos y allí, en ese lugar que le dicen el Camino de Dios, encontramos otra vez al gobierno tirando a matar." El llano en llamas, Op. cit., pp. 77-81.

Preciado:

19. Cf. el diálogo entre Pedro Páramo y Eduviges que ésta refiere a Juan

"Yo le pregunté muchos meses después a Pedro Páramo por ella.

'-Quería más a su hermana que a mï. Allá debe estar a gusto. Además, ya me tenia enfadado. No pienso inquirir por ella, si es eso lo que te preocupa.

¿¿Pero de qué vivirán?

"Que Dios los asista'" (p. 23). Como es sabido, la frase hecha tiene dos significados: uno, literal; otro, por antífrasis, 'que se las arreglen': el que Pedro Páramo aplica en este diálogo.

20. En varios casos, las transiciones entre las secuencias de las dos vertientes narrativas de la novela aparecen, a la primera lectura, simplemente como yuxtaposiciones discontinuas, cuando en rigor son enigmas cuya solución se entiende a la luz del contexto total. Asi, por ejemplo, la breve secuencia de la página 24, que termina con la admonición de la abuela al díscolo Pedro Páramo ("Siento que te va a ir mal, Pedro Páramo".) está seguida por el relato que Eduviges hace a Juan Preciado de la muerte de Miguel (pp. 25-27). Dentro de la organización total del texto, la conexión es muy clara: con la muerte de Miguel empieza a irle mal a Pedro Páramo, como él mismo lo reconoce (p. 72). Por otra parte, la muerte de Lucas Páramo prefigura la de Miguel (pp. 27-28): este enigma sólo se resuelve en la página 71.

21. Reiteremos una vez más que tanto los modelos lingüî̀sticos como las líneas históricas o los arquetipos míticos están siempre subordinados a la organización del relato. 